\title{
Biochemical and functional characterisation of secreted phospholipase activities from Cryptococcus neoformans in their naturally occurring state
}

\author{
ROSEMARY T. SANTANGELO* $\ddagger, M$. HOSSEIN NOURI-SORKHABI§, TANIA C. SORRELL*, \\ MICHELLE CAGNEY*†, SHARON C. A. CHEN*, PHILIP W. KUCHEL $\S$ and LESLEY C. WRIGHT* \\ * Centre for Infectious Diseases and Microbiology and tDepartment of Infectious Diseases, University of \\ Sydney, Westmead Hospital, Westmead, $\$$ Department of Biological Sciences, University of Western Sydney, \\ Nepean, Kingswood and §Department of Biochemistry, University of Sydney, Sydney New South Wales, \\ Australia
}

\begin{abstract}
A recent study demonstrated that phospholipase B (PLB), lysophospholipase (LPL) and lysophopholipase transacylase (LPTA) are secreted by Cryptococcus neoformans var. neoformans and showed that the amount of enzyme production correlated with virulence in mice. The present study characterised the extracellular enzyme activities further by radiometric assays and ${ }^{31} \mathrm{P}$ nuclear magnetic resonance spectroscopy (NMR). All three enzymes were most active between 25 and $40^{\circ} \mathrm{C}$. Bovine lung surfactant and its major lipid components, disaturated phosphatidylcholine and phosphatidylglycerol, were the optimal substrates for PLB. Lysophosphatidylcholine was the favoured substrate for LPL and LPTA. PLB and LPL/LPTA were differentially affected by Triton X-100, and palmitoyl carnitine was a potent inhibitor of the three phospholipases. LPL and PLB activities were inhibited by dithiothreitol; N-ethylmaleimide inhibited LPL and LPTA activities. None of the enzymes was inhibited by $\mathrm{N}$-bromosuccinimide or $p$-bromophenacyl bromide. Cellular disruption experiments indicated that $>85 \%$ of the phospholipase activities were cell-associated, with LPL and LPTA being more easily released than PLB. At pH 5.5 and 7.0, the heat-inactivated secreted enzyme preparations decreased the viability of human neutrophils. This effect was attenuated by active supernates. The relative activities of the PLB, LPL and LPTA in the environment of neutrophils are likely to determine the fate of these cells in vivo. Both phospholipases and heat-stable substances secreted by $C$. neoformans at $37^{\circ} \mathrm{C}$ could contribute to membrane degradation and virulence.
\end{abstract}

\section{Introduction}

The destructive effect of secretory phospholipases found in snake venoms, and arthropod and bacterial toxins, has been well documented [1]. The role of secretory phospholipases in disease states such as arthritis and adult respiratory distress syndrome has also been established [2,3]. Extracellular phospholipases are involved in the pathogenesis of certain

Received 8 Sept. 1998; revised version accepted 1 Dec. 1998. Corresponding author: Dr L. C. Wright (e-mail: lesleyw@ icpmr.wsahs.nsw.gov.au).

§Present address: James Fairfax Institute of Pediatric Nutrition, The New Children's Hospital, Westmead, NSW 2145, Australia. bacterial infections [4] and may contribute to virulence in fungal infections [5-7].

An earlier study identified three extracellular phospholipases produced by a clinical isolate of Cryptococcus neoformans var. neoformans [8]. These activities were defined as phospholipase B, (PLB, EC 3.1.1.5), lysophospholipase (LPL, EC 3.1.1.5) and lysophospholipase transacylase (LPTA, EC 3.1.1.5). No other phospholipase activities (A, C or D) were found [8]. All enzyme activities were stable and optimally active in the acidic $\mathrm{pH}$ range. When mice were infected with cryptococcal strains of different phospholipase-producing capacity, the high phospholipase-producing strains resulted in significantly higher numbers of organisms in the brain and lungs of the mice, and greater morbidity in affected animals [9]. Other potential virulence 
factors, such as the ability to grow at $37^{\circ} \mathrm{C}$, the presence of a polysaccharide capsule, melanin and mannitol production, have been described for $C$. neoformans [10-12] and a combination of these factors may account for the virulence of the fungus.

The mechanisms by which extracellular phospholipases influence cryptococcal pathogenicity are unknown, but bacterial phospholipases cause damage to host cell membranes, allowing tissue invasion [13]. Cryptococci are believed to enter the body following inhalation into lung alveoli, the surfaces of which are coated with surfactant, an agent which lowers surface tension at the air-fluid interface. Surfactant is composed mainly of phospholipids produced in acidic lamellar bodies within alveolar type II epithelial cells. Subsequent tissue invasion would be facilitated by degradation of epithelial cell-membrane phospholipids from either side of the bilayer, as membrane lipids are arranged asymmetrically in eukaryotes. The present study sought to characterise the behaviour of the secreted cryptococcal phospholipases in crude cryptococcal supernates, where other secreted substances, such as mannitol [12] and acetic acid [8], are present, a situation likely to be encountered in vivo. Temperature profiles and response to modifying agents were investigated, and a wide range of lipids, including surfactant, were tested as possible substrates for the phospholipase activities. Human neutrophils were chosen as model cells to assess membrane degradation, as these cells are viable at acidic $\mathrm{pH}$, at which the phospholipases are most active [8].

\section{Materials and methods}

\section{Materials}

These were obtained as follows: $1-\left[1-{ }^{14} \mathrm{C}\right]$ palmitoyl2-lysophosphatidylcholine $\quad(56.7 \mathrm{mCi} / \mathrm{mmol}), \quad 1,2-\mathrm{di}$ $\left[1-{ }^{14} \mathrm{C}\right]$ palmitoyl-phosphatidylcholine $(112 \mathrm{mCi} / \mathrm{mmol})$ (Amersham Life Sciences, Buckinghamshire); 1-palmitoyl-2-lyso-phosphatidylcholine (lyso-PC), dipalmitoylphosphatidylcholine (DPPC), dioleoyl phosphatidylcholine (DOPC), phosphatidylglycerol (PG), phosphatidylinositol (PI), DL- $\alpha$-phosphatidyl- $\mathrm{N}^{\prime} \mathrm{N}^{\prime}$-dimethylethanolamine (DMPE), phosphatidylserine (PS), phosphatidylethanolamine (PE), dipalmitoyl phosphatidic acid (DPPA) (Sigma); Sabouraud's Dextrose Agar (SDA; Difco Laboratories Detroit, MI, USA); solvents were of the highest available purity (Mallinckrodt, Clayton, Victoria, Australia). Unless otherwise specified, additional reagents were purchased from Sigma and were of the highest available purity. Bovine lung surfactant (Survanta) was kindly donated by Abbott Laboratories (Abbott Australasia, Sydney, NSW, Australia).

\section{Organism and enzyme preparations}

A clinical isolate of $C$. neoformans var. neoformans (BL-1, serotype A from human lung) was selected for enzyme preparation, as it exhibited high phospholipase activity when grown on SDA supplemented with $2 \mathrm{mM} \mathrm{Ca}^{2+}$ and egg-yolk $2 \% \mathrm{v} / \mathrm{v}$ [9]. Working cultures were stored at $4^{\circ} \mathrm{C}$ on SDA and were subcultured every 2 weeks.

\section{Preparation of cryptococcal supernates containing extracellular enzymes}

These were prepared by the method of Chen et al. $[8,9]$. Strain BL-1 was grown to confluence on SDA for $72 \mathrm{~h}$ at $30^{\circ} \mathrm{C}$, washed and resuspended in harvesting buffer ( $10 \mathrm{mM}$ imidazole, $2 \mathrm{M} \mathrm{CaCl}, 2 \mathrm{mM} \mathrm{MgCl}_{2}$, $56 \mathrm{mM}$ D-glucose, in $\mathrm{NaCl} 0.9 \% \mathrm{w} / \mathrm{v}, \mathrm{pH} 5.5$ ) for incubation $\left(20-24 \mathrm{~h}\right.$ at $\left.37^{\circ} \mathrm{C}\right)$. The cell-free supernate was assayed for total protein content and stored at $-70^{\circ} \mathrm{C}$ until required.

\section{Preparation of cell homogenates containing intracellular phospholipases}

Cryptococci were harvested after growth for $72 \mathrm{~h}$ at $30^{\circ} \mathrm{C}$ on SDA and subjected to disruption either immediately or after further incubation at $37^{\circ} \mathrm{C}$ for $20-24 \mathrm{~h}$ in harvesting buffer. Non-disrupted controls were assayed in parallel [14]. One volume each of glass beads $(0.4 \mathrm{~mm}$ diameter, acid washed; Sigma), digestion buffer ( $50 \mathrm{mM}$ imidazole, $1 \mathrm{mM}$ EDTA, $\mathrm{pH} 7$ ) and distilled water was added to two volumes of packed cryptococcal cells. A protease inhibitor mixture containing a Complete Mini protease inhibitor cocktail tablet (Boehringer Mannheim, Germany), $100 \mathrm{mM} \mathrm{N}-\alpha-$ p-tosyl-L-arginine methyl ester and $10 \mu \mathrm{M}$ pepstatin was added to all samples at a 1 in 10 dilution. Samples were homogenised mechanically (LR 270, HD Scientific, Kings Park NSW, Australia) and freeze-thawed in liquid nitrogen for c. $30 \mathrm{~min}$. Homogenates were removed and the glass beads were washed once with imidazole-acetate buffer ( $50 \mathrm{mM}, \mathrm{pH} 4.0)$. Rinses were pooled with homogenates, centrifuged at $13000 \mathrm{~g}$ for $15 \mathrm{~min}$ and the supernates were collected. The pellets were washed and re-centrifuged; the supernates were removed and pooled with the previous samples. All samples were assayed for total protein content and enzyme activity. Successful mechanical disruption was confirmed by fluorescence microscopy of pellet fractions stained with propidium iodide (in $10 \mathrm{mM}$ HEPES

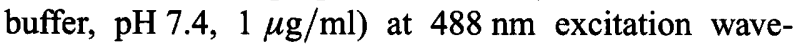
length and with a 515-nm longpass filter for detection.

\section{Assays of phospholipase activity}

Radiometric assay. Enzyme activities were assayed at $\mathrm{pH} 4.0$ by the method described by Chen et al. $[8,9]$. Reaction rates were measured by the decrease of radioactivity in $1,2-\mathrm{di}\left[1-{ }^{14} \mathrm{C}\right] \mathrm{DPPC}$ (radioactive fatty acids are released). LPL activity was measured by the loss of radiolabelled $1-\left[1-{ }^{14} \mathrm{C}\right]$ palmitoyl lyso-PC. LPTA activity was determined by the relative formation of radiolabelled DPPC from $1-\left[1-{ }^{14} \mathrm{C}\right]$ palmitoyl lysoPC. 
Reactions were initiated by the addition of culture supernate (1-3 $\mu \mathrm{g}$ total protein, $0.25 \mathrm{ml}$ total volume), followed by incubation at $37^{\circ} \mathrm{C}$ for $22 \mathrm{~min}$ (PLB) or $15 \mathrm{~s}$ (LPL and LPTA) and were stopped by the addition of four volumes of chloroform:methanol (2:1, v:v). Reaction products were extracted by the method of Bligh and Dyer [15] and quantified as described by Chen et al. $[8,9]$.

NMR spectroscopy. Potential substrates $(2-3 \mathrm{mg})$ were resuspended and dispersed by tip sonication in $200 \mu \mathrm{l}$ of assay buffer with or without Triton X-100 (final concentration $0.33 \% \mathrm{w} / \mathrm{v}$ ) and transferred to a $10-\mathrm{mm}$ outer diameter NMR tube containing $1 \mathrm{ml}$ of ${ }^{2} \mathrm{H}_{2} \mathrm{O}$ and enzyme preparation (final protein concentration $10 \mu \mathrm{g} / \mathrm{ml})$.

${ }^{31} \mathrm{P}$ NMR spectra were obtained on a Bruker AMX-400 wide-bore NMR spectrometer operating at $161.98 \mathrm{MHz}$ in the Fourier transform mode [8], with the probe temperature maintained at $37^{\circ} \mathrm{C} \pm 1^{\circ} \mathrm{C}$. Spectra were generated with rapid pulsing according to the method of Homer and Roberts [16]. Broad-band proton decoupling (WALTZ-16) [17] was applied to eliminate ${ }^{1} \mathrm{H}-{ }^{31} \mathrm{P}$ NMR peak multiplicities. Other parameters were similar to those used previously [8]. All free induction decays (FID) of the spectra shown (Fig. 2) were processed with $2 \mathrm{~Hz}$ line broadening; however, for quantification of lipid breakdown rates no line broadening was used. Peak areas corresponding to substrates or reaction products were determined after Lorentzian deconvolution, and used to determine the relative percentage of substrate hydrolysed or product formed in rate calculations. These percentages were derived from the initial rates obtained by plotting the changes in areas with time. Chemical shift data, $(\delta)$ were expressed as parts per million (ppm) and assignment of resonances to reaction products was confirmed by the addition of authentic standards.

\section{Effect of various agents on enzyme activity}

Enzyme activities were assayed by the radiometric method described above, and modifying agents were added to assay mixtures at the desired concentration following sonication of the substrate. Substances were prepared as stock solutions in assay buffer with the exception of palmitoyl carnitine which was prepared as a stock in methanol. The final concentration of methanol added to reaction mixtures was $<0.1 \% \mathrm{v} / \mathrm{v}$ and was present in controls.

\section{Isolation of neutrophils}

Neutrophils were isolated from healthy Blood Bank volunteers as described previously [18] and resuspended in calcium- and magnesium-free phosphatebuffered saline $\mathrm{PBS}^{-}$. Cell purity $(\geqslant 90 \%)$ was monitored by Coulter counter (Hialeah, FL, USA) and viability was assessed by trypan blue exclusion and propidium iodide uptake (see below).

\section{Incubation of neutrophils with cryptococcal} supernates

Neutrophils $\left(10^{8}\right)$ were incubated in $5 \mathrm{ml}$ of Hank's Balanced Salts Solution (HBSS) for $1 \mathrm{~h}$ at $37^{\circ} \mathrm{C}$ with agitation then treated with active or heat-inactivated $\left(90^{\circ} \mathrm{C}\right.$ for $\left.10 \mathrm{~min}\right)$ cryptococcal supernate. Supernate phospholipase activities were measured before and after inactivation. A volume of cryptococcal supernate (capable of hydrolysing $1.6 \mu \mathrm{molDPPC} / \mathrm{min} / \mathrm{mg}$ of protein) was diluted 1 in 2 in harvesting buffer, adjusted to $\mathrm{pH} 5.5$ or 7.0 , and added to neutrophils $\left(2 \times 10^{7}\right)$ in a final volume of $1.5 \mathrm{ml}$. Samples were incubated at $37^{\circ} \mathrm{C}$ for $90 \mathrm{~min}$ with gentle agitation. Control cells were incubated in harvesting buffer (pH 5.5 or 7.0 ).

Endotoxin was assayed with the E-toxate kit (Sigma). The native and heat-inactivated enzyme preparations, as well as the harvesting buffer used for the controls, contributed similar low levels of endotoxin to the reaction mixtures $(<10 \mathrm{ng} / \mathrm{ml})$.

\section{Estimation of neutrophil viability by flow cytometry}

Annexin V-Fluos (Boehringer-Mannheim) and propidium iodide (Sigma) $50 \mu \mathrm{g} / \mathrm{ml}$ were used to label triplicate neutrophil samples according to the manufacturers' instructions, and the fluorescence was recorded on an EPICS Profile II Analyzer (Coulter). Annexin $\mathrm{V}$ binds to phosphatidylserine (PS) exposed on the outer leaflet of the plasma membrane of apoptotic cells, which have intact membranes and are impermeable to propidium iodide, in contrast to necrotic cells. Forward angle light scatter and side scatter were measured for each sample. Fluorescence was quantified with an excitation wavelength of $488 \mathrm{~nm}$ and a 530-nm bandpass filter for fluorescein and a $>575-\mathrm{nm}$ bandpass filter for propidium iodide.

\section{Protein estimations}

Protein concentrations were determined with the BioRad Protein assay kit (BioRad, Ryde, NSW, Australia). Bovine serum albumin was used as the standard.

\section{Statistical calculations}

All statistical calculations were performed with the computer programme Instat version 1.13 (GraphPad, San Diego, CA, USA).

\section{Results}

\section{Effect of temperature on phospholipase activity}

Growth at $37^{\circ} \mathrm{C}$ is a property which contributes to cryptococcal virulence [10]. If extracellular phospholipases are important in the pathogenesis of human infection, activity at $37^{\circ} \mathrm{C}$ should be demonstrable. The present study determined the temperature at which 
enzyme activities were maximal and also their thermal stability. Samples were assayed at $4^{\circ} \mathrm{C}, 25^{\circ} \mathrm{C}, 37^{\circ} \mathrm{C}$ or $40^{\circ} \mathrm{C}$ or incubated at $40^{\circ}-100^{\circ} \mathrm{C}$ for $10 \mathrm{~min}$ before assay at $37^{\circ} \mathrm{C}$. PLB and LPL activities were maximal at $25^{\circ}-40^{\circ} \mathrm{C}$ (Fig. 1a). The response of LPTA to temperature was similar to that of LPL (data not shown). At $4^{\circ} \mathrm{C}$ only 20,35 and $25 \%$ of the maximum percentage of substrate hydrolysed or formed was achieved for PLB, LPL and LPTA, respectively. Preincubation of enzyme preparations at temperatures between $40^{\circ}$ and $100^{\circ} \mathrm{C}$ before assay at physiological temperature affected LPL and PLB differently (Fig. 1b). LPTA behaved similarly to LPL (data not shown). While it was apparent that activity declined dramatically when both enzymes were exposed to temperatures $\geqslant 60^{\circ} \mathrm{C}$, maximal LPL activity decreased by only $40 \%$ after pre-treatment at $60^{\circ} \mathrm{C}$ compared with $90 \%$ for PLB (Fig. 1b). No significant enzyme activity was detected after exposure to temperatures $\geqslant 70^{\circ} \mathrm{C}$ for $10 \mathrm{~min}$.

\section{Substrates of cryptococcal phospholipases}

A previous report demonstrated that DPPC and lyso-PC are substrates of cryptococcal phospholipases [8]. Alternative substrates of PLB and LPL were investigated by ${ }^{31} \mathrm{P}$ NMR spectroscopy. Except for DPPC, the presence of the non-ionic detergent, Triton X-100, enhanced the rates of hydrolysis by PLB of all of diacylphospholipids examined (Table 1). Conversely, the rate of hydrolysis of all lysophospholipids (excluding lysophosphatidylethanolamine) was reduced (data not shown). Phospholipids were hydrolysed by PLB at rates in the following order of preference in the presence of Triton X-100: DPPC $>$ PG $>$ PI $>$ DMPE $>$ egg PC $>$ DOPC $>$ PS $>$ egg PE $>$ brain PE (Table 1).

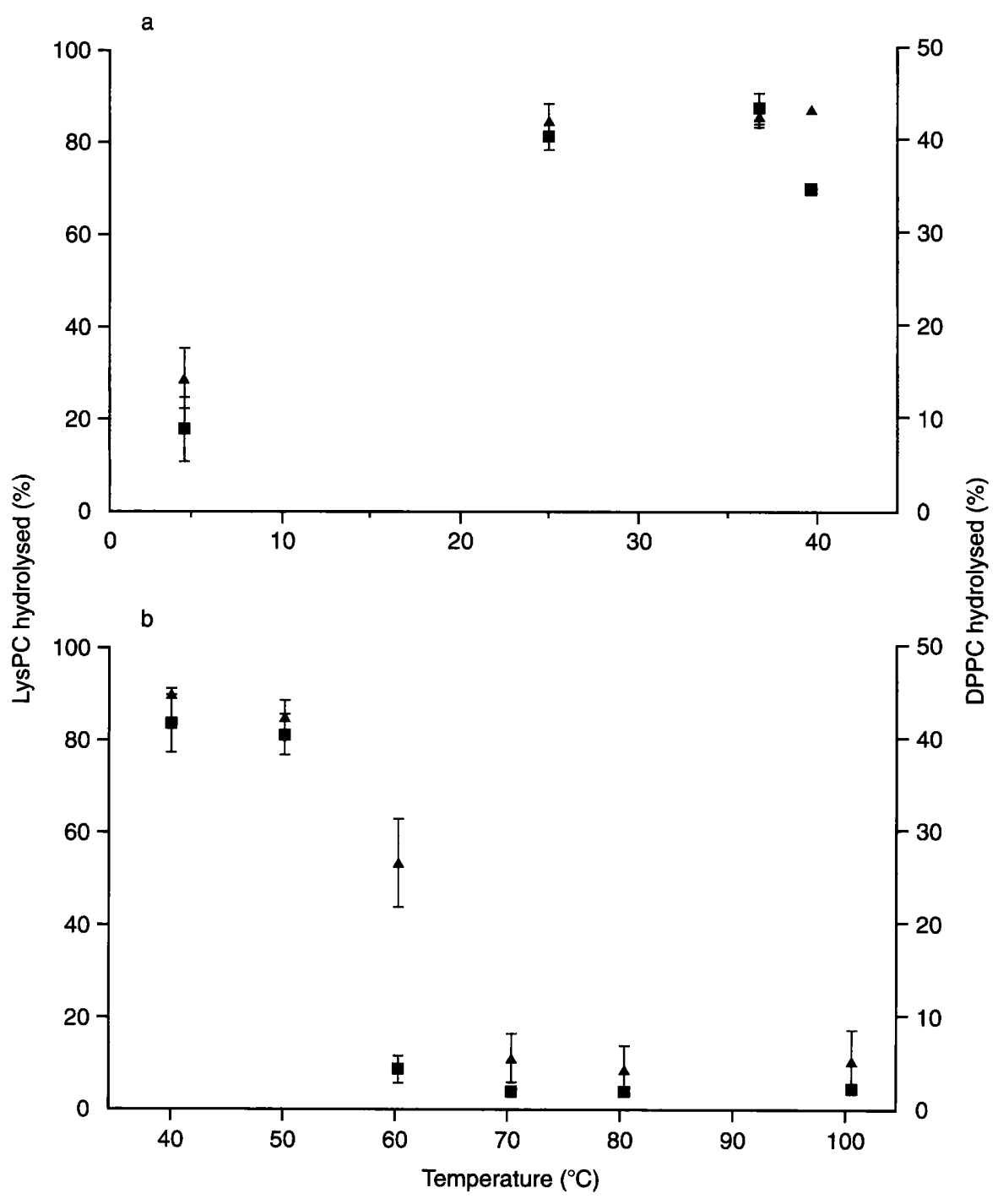

Fig. 1.(a) The effect of assay temperature on the LPL and PLB activities of $C$. neoformans. Data are represented as the

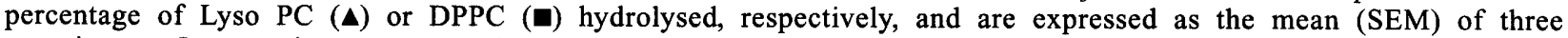
experiments. In some instances error bars cannot be seen because they were less than symbol size. (b) The stability of LPL and PLB activities of $C$. neoformans after pre-incubation for $10 \mathrm{~min}$ at the specified temperature, before assay at

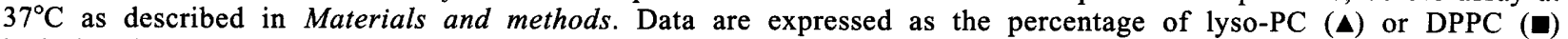
hydrolysed, respectively, and represent the mean (SEM) of three experiments. In some instances the error bars cannot be seen as they were less than the symbol size. 
Table 1. The rates of hydrolysis of various phospholipids in the presence or absence of Triton X-100 by the PLB of $C$. neoformans, determined by ${ }^{31} \mathrm{P}$ NMR spectroscopy

\begin{tabular}{|c|c|c|}
\hline Substrate & Presence of Triton $\mathrm{X}-100^{*}$ & $\begin{array}{c}\text { Rate }(\mu \mathrm{mol} / \mathrm{min} / \mathrm{mg} \\
\text { of protein })^{\dagger}\end{array}$ \\
\hline DPPC (synthetic) & + & $5.1(\mathrm{SEM} 0.6)^{\ddagger}$ \\
\hline DPPC (synthetic) & - & $6.2(\text { SEM } 1.7)^{\ddagger}$ \\
\hline Surfactant (bovine lung) & + & $4.7(\mathrm{SEM} 0.7)^{\ddagger}$ \\
\hline Surfactant (bovine lung) & - & $6.2($ SEM 1.1) \\
\hline PG (egg-yolk) & + & $2.3(\text { SEM } 0.5)^{\ddagger}$ \\
\hline PG (egg-yolk) & - & 0.6 \\
\hline PI (soybean) & + & 1.9 \\
\hline PI (soybean) & - & BLD \\
\hline DMPE (synthetic) & + & 1.5 \\
\hline Egg PC & + & 1.1 \\
\hline DOPC (synthetic) & + & 1.0 \\
\hline DOPC (synthetic) & - & 0.5 \\
\hline PS (bovine brain) & + & $0.8 \pm 0.02^{\S}$ \\
\hline PS (bovine brain) & - & $\mathrm{BLD}^{\S}$ \\
\hline PE (brain) & + & $0.3 \pm 0.2^{\S}$ \\
\hline PE (brain) & - & $\mathrm{BLD}^{\S}$ \\
\hline Alkyl oleoyl PC (synthetic) & + & $\mathrm{BLD}^{\ddagger}$ \\
\hline Alkyl palmitoyl PC (synthetic) & + & $\mathrm{BLD}^{\S}$ \\
\hline DPPA (synthetic) & + or - & $\mathrm{BLD}^{\S}$ \\
\hline Cardiolipin (synthetic) & + or - & $\mathrm{BLD}^{\S}$ \\
\hline Sphingomyelin & + or - & $\mathrm{BLD}^{\S}$ \\
\hline
\end{tabular}

BLD, below level of detection.

* The concentration of Triton X-100 was $0.33 \% \mathrm{w} / \mathrm{v}$.

${ }^{\dagger}$ Rates were calculated from the amount of substrate hydrolysed, or product formed, over time and are expressed as $\mu \mathrm{mol}$ of substrate hydrolysed, or product formed, $/ \mathrm{min} / \mathrm{mg}$ of protein. Peak areas were determined by Lorentzian deconvolution without line broadening (see Materials and methods) and were used to determine the percentage of substrate hydrolysed or product formed in these calculations.

${ }^{\ddagger}$ Mean (SEM) of three experiments. ${ }^{\S}$ Mean \pm range of two experiments; all other data are the result of one experiment only.

Phospholipids that were not hydrolysed in either the presence or absence of Triton X-100 included alkyl oleoyl PC, alkyl palmitoyl PC, DPPA, cardiolipin and sphingomyelin (Table 1). LPL hydrolysed lysophospholipids in the following order of rates in the absence of Triton X-100 when examined by ${ }^{31} \mathrm{P}$ NMR spectroscopy: lyso-PC >lyso-PG >lyso-PE >lyso-PI. No hydrolysis was observed for lyso-PA (data not shown).

Bovine lung surfactant, of which DPPC is the primary component, was hydrolysed at a rate similar to DPPC when examined by NMR spectroscopy and, like DPPC, the rate was lower in the presence of Triton X-100 (Table 1). Although surfactant contains other phospholipids, e.g., PG $(\delta, 0.983 \mathrm{ppm})$ these were not visible in the ${ }^{31} \mathrm{P}$ NMR spectra (Fig. 2) due to their relatively low concentration compared with DPPC $(\delta,-0.211 \mathrm{ppm})$. Surfactant DPPC decreased over time with a corresponding increase in the sole product glycerophosphocholine $(\delta, 0.64 \mathrm{ppm})$. The absence of phosphatidic acid, lysophosphocholine or phosphocholine confirmed previous observations [8] that the phospholipase activity of $C$. neoformans was due to PLB rather than phospholipases $\mathrm{D}, \mathrm{A}$ or $\mathrm{C}$.

\section{Effect of modifying agents on phospholipases}

Modifying agents, selected for their reported effects on other fungal lipases, were tested in the radiometric assay (to avoid difficulty in interpretation of NMR spectra caused by the presence of interfering or overlapping resonances). DPPC or lyso-PC were used as substrates for PLB and LPL/LPTA activity, respectively. The most effective concentrations are indicated in Table 2. Cryptococcal PLB was resistant to the effects of many agents examined and in some cases responses that differed from cryptococcal LPL/LPTA activities were observed. In contrast to the results obtained with DPPC by ${ }^{31} \mathrm{P}$ NMR (Table 1), a small but significant enhancement of PLB activity $(29 \%)$ was observed in the presence of $0.33 \% \mathrm{w} / \mathrm{v}$ Triton $\mathrm{X}-100$ in the radiometric assay $(\mathrm{p}=0.0385$, paired two-tailed, $t$ test, Table 2). LPL activity was inhibited by $43 \%$ under the same conditions, a result comparable to that obtained by NMR spectroscopy (data not shown). All three enzyme activities were dramatically reduced in the presence of sodium dodecyl sulphate $0.03,0.05$ and $0.10 \% \mathrm{w} / \mathrm{v}$ (data not shown).

High concentrations of dithiothreitol (10 mM) and methanol $(10 \% \mathrm{v} / \mathrm{v})$ significantly inhibited PLB activity $(39 \%$ and $23 \%$, respectively). Similarly, LPL activity appeared to be reduced under the same conditions $(n=2$, Table 2). Palmitoyl carnitine, a competitive inhibitor of a mammalian LPL/LPTA [19] significantly inhibited all three cryptococcal phospholipases (Table 2). PLB activity was reduced by $50 \%$ and $86 \%$ in the presence of $50 \mu \mathrm{M}$ and $1 \mathrm{mM}$ palmitoyl 

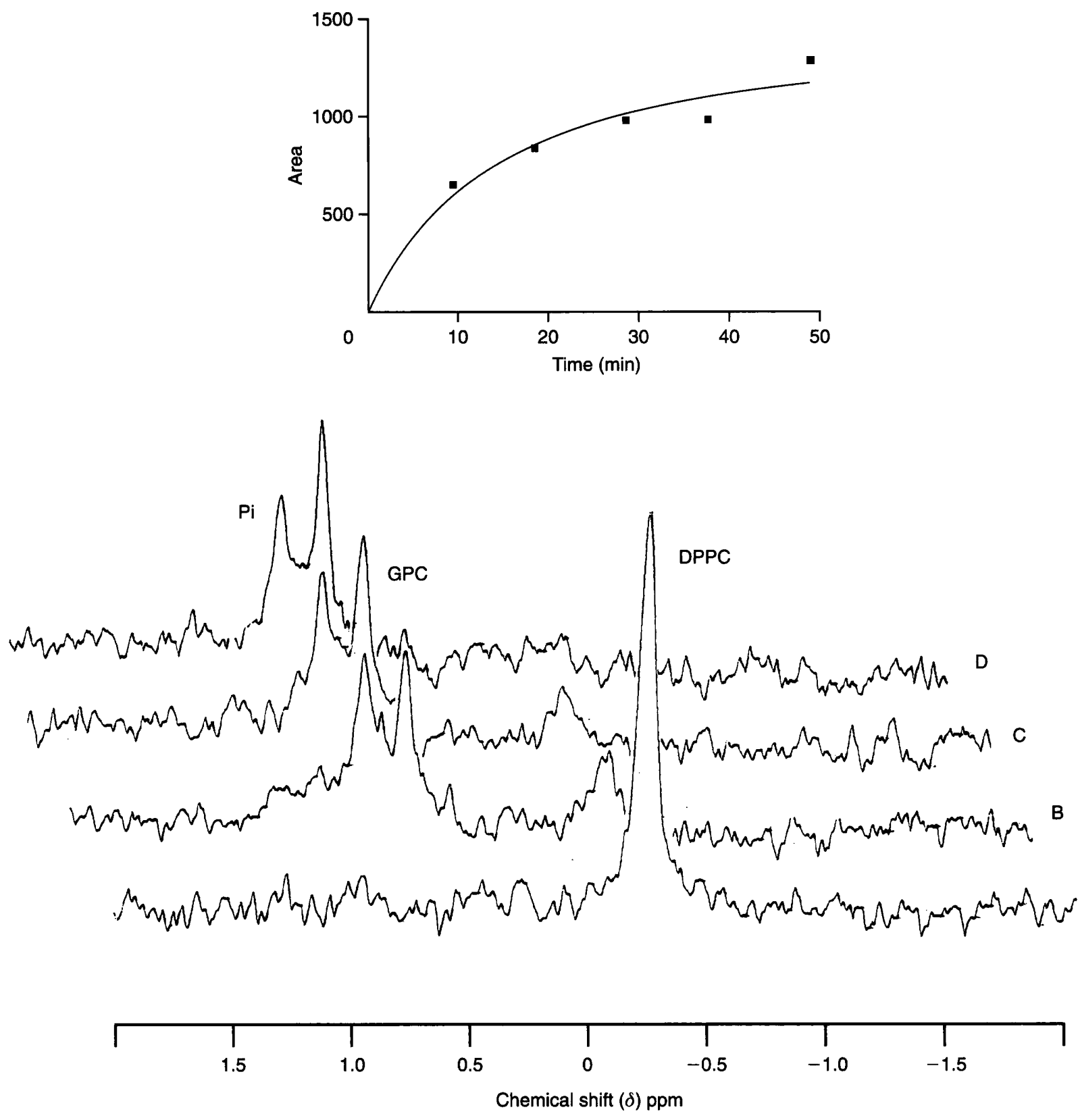

Fig. 2. Sequential ${ }^{31} \mathrm{P}$ NMR spectra showing the hydrolysis of bovine lung surfactant over time by cryptococcal PLB in the presence of Triton X-100. The glycerophosphocholine (GPC) and DPPC peak intensities increased and decreased, respectively, with time. $\mathbf{A}$ is the spectrum of surfactant before addition of enzyme (zero time); $\mathbf{B}, \mathbf{C}$ and $\mathbf{D}$ were spectra acquired at 19, 28 and $48 \mathrm{~min}$ respectively. $P_{i}$ denotes inorganic phosphate present in the enzyme preparation $(0.798 \mathrm{ppm})$. The complete time course for the formation of GPC, measured by the area under the peak (arbitrary units), is shown in the inset.

carnitine, respectively; LPL and LPTA activities were reduced by $37 \%$ and $50 \%$, respectively, at a concentration of $1 \mathrm{mM}$, only (Table 2). Carnitine inhibited LPL and LPTA activities by $37 \%$ and $35 \%$, respectively, whereas PLB activity was marginally enhanced (12\%) (Table 2).

Sulphydryl-reactive compounds, such as Ellman's reagent and $\mathrm{N}$-ethylmaleimide, appeared to inhibit LPL and LPTA activities by up to $22 \%$ and $32 \%$, respectively. The $\mathrm{PLA}_{2}$ inhibitor, $p$-bromophenacyl bromide [20], appeared to increase the LPL/LPTA activities $(n=2)$ [20]. Mild enhancement $(18 \%$ and $10 \%$ ) of PLB activity was noted in the presence of phenylglyoxal or tripolyphosphate $(n=2)$.

\section{Cell-associated phospholipase activity}

Most of the total phospholipase activity in cryptococci was cell-associated $(\geqslant 85 \%)$. However, high levels of both LPL/LPTA and PLB activities were released by mechanical disruption of cryptococci; in samples disrupted immediately after harvest (Table 3a), almost five-fold more LPL/LPTA activity was released com- 


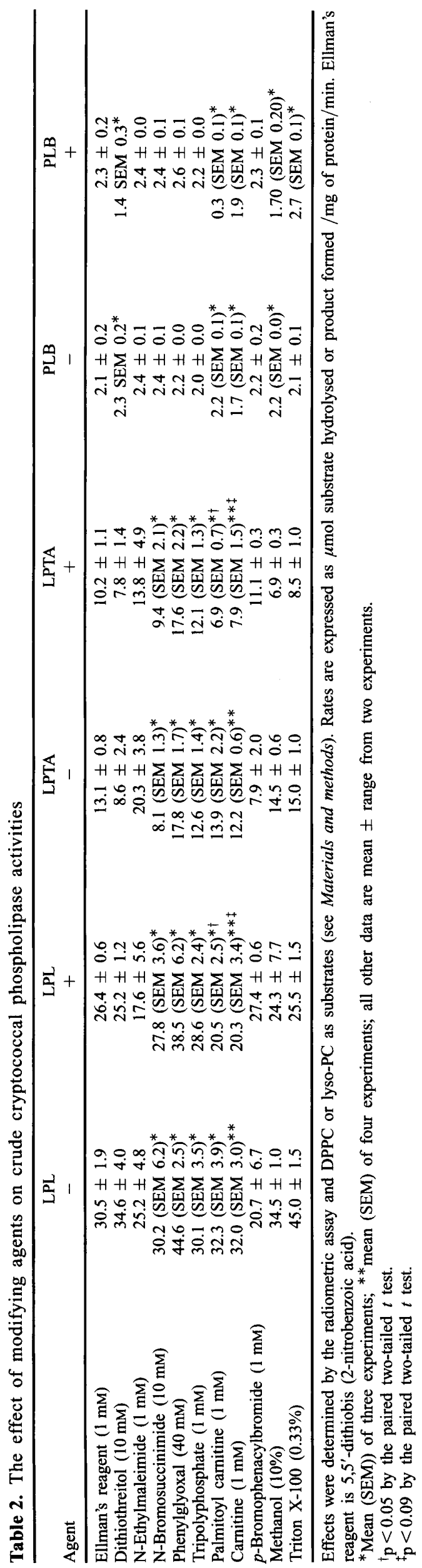

pared with that of PLB. LPL/LPTA activity released by disruption of cells pre-incubated for 20-24 $\mathrm{h}$ was reduced by $c$. 10 -fold (Table $3 b$ ), presumably because the phospholipase activity had been secreted before cell disruption took place. In contrast, cell-associated LPL and LPTA activity in pre-incubated samples was not significantly different from cell-associated PLB activity. The proportions of phospholipase activities secreted after incubation for $24 \mathrm{~h}$ were calculated to be $15,5.6$ and $3.7 \%$ of the total cryptococcal activity measured (cell-associated plus extracellular) for PLB, LPL and LPTA, respectively.

\section{Effect of cryptococcal supernates on neutrophil membranes}

The exposure of PS on the outside of cells, including neutrophils [21], is an indicator of the onset of apoptosis. The effects on neutrophil membranes of cryptococcal supernates containing active or heat-inactivated (85$90^{\circ} \mathrm{C}$ for $10 \mathrm{~min}$ ) phospholipases were examined with different batches of cells at pH 5.5 and 7.0 (Table 4). Neutrophils in $\mathrm{PBS}^{-}$assayed before incubation (zero time) contained similar percentages of necrotic and apoptotic cells to the control cells, incubated in the buffers alone. At both $\mathrm{pH}$ values, the heat-inactivated enzyme preparations decreased the number of normal cells and increased the numbers of apoptotic and necrotic cells compared with the controls (Table 4). Interestingly, the preparations containing the active phospholipases produced more normal cells and fewer necrotic cells than the heat-inactivated supernates at both $\mathrm{pH} 5.5$ and 7.0; at pH 7.0 the active supernate produced cells of similar viability to the control (Table 4).

\section{Discussion}

In the present study, the secreted PLB, LPL and LPTA activities of a clinical isolate of $C$. neoformans var. neoformans were characterised in their crude state, because in other fungi all three enzyme activities do not simultaneously survive the purification process $[22,23]$. C. neoformans is able to grow at $37^{\circ} \mathrm{C}$, a factor that contributes to its virulence [10]. It is apparent from the present study that cryptococcal phospholipases are also optimally active at physiological temperatures (Fig. 1a and 1b). PLB, LPL and LPTA activities measured at $4^{\circ} \mathrm{C}$ were reduced to $c .15,30$ and $25 \%$ of those at $37^{\circ} \mathrm{C}$, respectively. The cryptococcal phospholipases were also stable at $-70^{\circ} \mathrm{C}$ for $>6$ months and survived $>20$ freeze-thaw cycles (unpublished observations).

${ }^{31} \mathrm{P}$ NMR spectroscopy was shown to be suitable for rapid, semi-quantitative screening of a wide range of potential lipid substrates of the enzymes. When Triton X-100 was present, the diacyl-and lyso-phospholipid substrates were visible in the spectra and both the disappearance of substrate and the appearance of water- 
Table 3. Cell-associated phospholipase activity of $C$. neoformans released by mechanical disruption

\begin{tabular}{|c|c|c|c|}
\hline Fraction & LPL activity (\%) & LPTA activity (\%) & PLB activity (\%) \\
\hline $\begin{array}{l}\text { Stage A } \\
\text { Control supernate } \\
\text { Disrupted cell supernate } \\
\text { Control pellet } \\
\text { Disrupted cell pellet }\end{array}$ & $\begin{array}{c}100(0.8 \text { SEM } 0.3) \\
1888 \text { SEM } 448^{\dagger \ddagger} \\
100(91.9 \text { SEM } 6.1) \\
248 \text { SEM } 4^{\dagger}\end{array}$ & $\begin{array}{c}100(0.4 \text { SEM 0.2) } \\
1867 \text { SEM } 707^{\S \#} \\
100(37.5 \text { SEM } 4.4) \\
183 \text { SEM } 41^{\natural}\end{array}$ & $\begin{array}{c}100(0.04 \text { SEM } 0.01) \\
395 \text { SEM } 27^{\dagger} \\
100(0.8 \text { SEM } 0.7) \\
495 \text { SEM } 395\end{array}$ \\
\hline $\begin{array}{l}\text { Stage B } \\
\text { Control supernate } \\
\text { Disrupted cell supernate } \\
\text { Control pellet } \\
\text { Disrupted cell pellet }\end{array}$ & $\begin{array}{c}100(7.5 \text { SEM 0.2) } \\
193 \text { SEM } 18^{\dagger * *} \\
100(138.4 \text { SEM } 29) \\
264 \text { SEM } 30^{\dagger}\end{array}$ & $\begin{array}{c}100(1.5 \text { SEM } 0.1) \\
178 \text { SEM } 17^{\dagger *} \\
100(41.9 \text { SEM } 8.4) \\
208 \text { SEM } 27^{\dagger}\end{array}$ & $\begin{array}{c}100(0.2 \text { SEM } 0.03) \\
298 \text { SEM } 44^{\dagger} \\
100(1.2 \text { SEM } 0.1) \\
281 \text { SEM } 186\end{array}$ \\
\hline \multicolumn{4}{|c|}{ 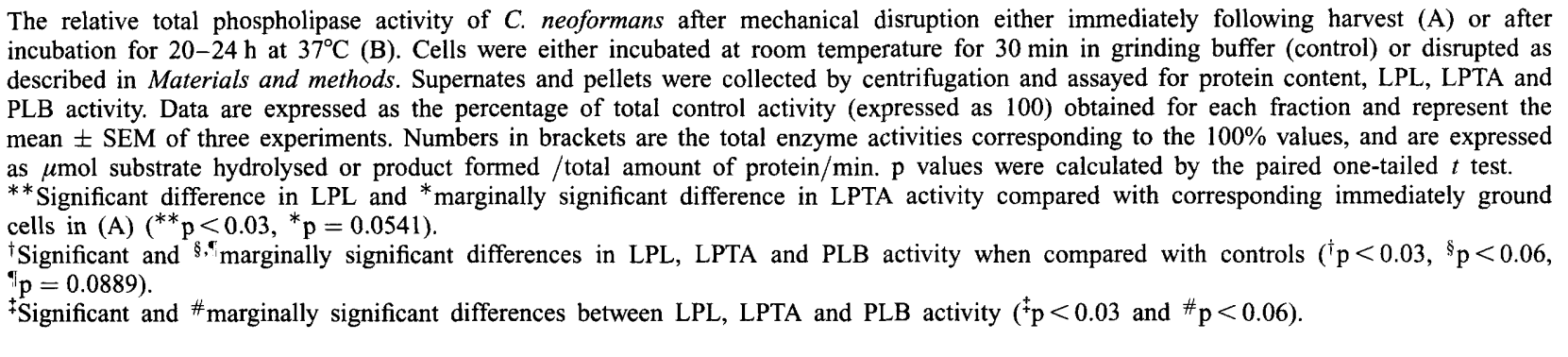 } \\
\hline
\end{tabular}

Table 4. The effects of cell-free cryptococcal supernates containing phospholipases on the viability of human neutrophils*

\begin{tabular}{lcrc}
\hline & \multicolumn{3}{c}{ Mean (SEM) percentage distribution of } \\
& \multicolumn{3}{c}{ neutrophils } \\
\cline { 2 - 4 } Treatment & Normal & Necrotic & Apoptotic \\
\hline pH 5.5 & & & \\
Zero time & $70.6(2.2)$ & $2.7(0.5)$ & $26.6(2.3)$ \\
Control & $71.7(3.2)$ & $3.4(0.7)$ & $24.6(2.9)$ \\
HI supernate & $48.9(7.3)^{\dagger}$ & $12.9(3.2)^{\dagger}$ & $37.8(4.9)^{\dagger}$ \\
Native supernate & $53.6(6.4)^{\dagger \S}$ & $10.3(2.7)^{\dagger \ddagger}$ & $35.7(4.7)^{\dagger}$ \\
pH 7.0 & & & \\
Zero time & $85.1(5.6)$ & $12.6(4.8)$ & $2.4(0.8)$ \\
Control & $87.0(2.3)$ & $8.8(1.4)$ & $4.2(0.9)$ \\
HI supernate & $80.3(3.9)^{\dagger}$ & $10.1(2.9)$ & $9.4(2.9)$ \\
Native supernate & $89.0(1.2)^{\#}$ & $6.2(0.5)$ & $4.8(1.4)^{\dagger}$ \\
\hline
\end{tabular}

* Neutrophils were assayed for viability by flow cytometry by FITCannexin $\mathrm{V}$ and propidium iodide binding before (zero time) or after incubation for $1 \mathrm{~h}$ with HBSS, followed by $1.5 \mathrm{~h}$ in growth buffer, pH 5.5 or 7.0 (control). Neutrophils were also treated after $1 \mathrm{~h}$ in HBSS with heat-inactivated cryptococcal supernate, $\mathrm{pH} 5.5$ or 7.0 for $1.5 \mathrm{~h}$ (HI supernate) or with untreated cryptococcal supernate pH 5.5 or 7.0 (native supernate). The results at pH 5.5 are expressed as the means (SEM) of eight separate experiments (12 experiments for zero time), assayed in duplicate or triplicate. Three experiments were performed at $\mathrm{pH}$ 7.0. Significance was determined by the twotailed, paired $t$ test.

${ }^{\dagger}$ Different from the controls, $\mathrm{p} \leqslant 0.005, \mathrm{pH} 5.5 ; \mathrm{p}=0.06, \mathrm{pH} 7.0$ Different from HI enzymes, ${ }^{\S} \mathrm{p}=0.07 ;{ }^{\ddagger} \mathrm{p}=0.0008 ;{ }^{\#} \mathrm{p}=0.05$; $\mathrm{i}=0.03$.

soluble product could be observed readily. In the absence of Triton X-100, the diacylphospholipids were not sufficiently mobile to be visible in the NMR spectra and only product formation could be measured. Lower rates of hydrolysis of DPPC were observed with the more accurate, sensitive radiometric assay compared with NMR spectroscopy, as well as an increase of activity in the presence of Triton X-100 (Tables 1 and 2). The stimulation of PLB activity in the presence of Triton X-100 with the inhibition of LPL activity is common to several fungal phospholipases [24-26], and the effects are probably due to the altered physical state of the substrates in the presence of the detergent.

Cryptococcal phospholipases can hydrolyse, to some extent, most of the major membrane phospholipids and lysophospholipids (Table 1). In contrast to PLB from the relatively non-pathogenic fungus, Penicillium notatum - where acidic, inner leaflet phospholipids PS, PI, PA are preferred substrates [24] - cryptococcal PLB showed greatest activity with DPPC, followed by PG. These are the two major phospholipid components of lung surfactant [26], and the finding that bovine lung surfactant was degraded at a rate similar to DPPC supports the hypothesis that cryptococcal PLB assists the organism to penetrate the surfactant lining of the alveolar epithelium.

The tryptophan-modifying agent, $\mathrm{N}$-bromosuccinimide, and $p$-bromophenacyl bromide (reportedly an effective inhibitor of mammalian phopholipase $\mathrm{A}_{2}$ [20] and $P$. notatum PLB and LPL [23] by alkylating a histidine residue at the active site), did not inhibit the activity of cryptococcal phospholipases (Table 2). Similarly, the arginine-modifying agent phenylglyoxal did not inhibit cryptococcal phospholipases, but was inhibitory to PLB and LPL from $P$. notatum [23].

Reduction in LPL/LPTA activities by sulphydryl blocking (oxidising) agents such as $\mathrm{N}$-ethylmaleimide and Ellman's reagent has been observed in purified preparations from Candida albicans [27] and in the present study, suggesting that cysteine residues are necessary for these activities. The sulphydryl reducing agent, dithiothreitol, inhibited PLB and LPL, but not LPTA from cryptococci, suggesting that these activities are associated with different active sites or separate proteins. 
The most effective and biologically important inhibitor of all three phospholipase activities was palmitoyl carnitine. Palmitoyl carnitine was not a substrate for the cryptococcal phospholipases (unpublished observation). Long-chain acyl carnitines are competitive inhibitors of LPL/LPTA activity in rabbit myocardium [19] and inhibit C. albicans LPTA as well as adherence of the fungus to lysophospholipids and HEp-2 cells [28]. However, palmitoyl carnitine enhanced LPL activity in $C$. albicans $[22,27]$. In contrast to the effects of palmitoyl carnitine, carnitine marginally inhibited cryptococcal LPL and LPTA activities, but did not inhibit PLB; therefore the addition of an acyl chain is required for binding to and inhibiting the cryptococcal phospholipases.

Most of the phospholipase activity in $C$. neoformans remained cell-associated after mechanical disruption. The location of these enzymes within the cell (cytoplasmic, organellar, membrane-bound, cell wall or periplasmic space) is unknown, but the data in Table 3 indicate that PLB, LPL and LPTA activities are released spontaneously over time, or immediately by mechanical disruption. Intracellular pools of enzyme activity have also been noted in Saccharomyces cerevisiae [29] and C. albicans [14], although the amount of total activity which is intracellular was not reported for these yeasts. The ratio of LPL/PLB activity in the supernate of $C$. neoformans cells disrupted immediately after harvesting was greater than that obtained after the cells were allowed to secrete the enzymes overnight (Table 3), suggesting that separate intracellular locations may exist for LPL and PLB.

Cryptococci are capable attenuators of neutrophil function [30,31]. The data in Table 4 indicate that cryptococcal secretions can also damage neutrophils in both neutral and acidic environments. An acidic environment may be created by the cryptococci themselves, as an earlier study reported that these fungi produce large amounts of acetic acid [8]. While the $\mathrm{pH}$ values created in the micro-environment of cryptococci in vivo are unknown, the $\mathrm{pH}$ of the phagolysosome of macrophages is $\leqslant 5.0$ [32] and in lung lamellar bodies (surfactant stores) is $\leqslant 6.1$ [33]. Cryptococci are known to survive ingestion by macrophages [34], possibly by preventing phagosome-lysosome fusion [35], an event which could be disrupted by phospholipases. The activity of PLB at pH 5.5 is only $c .5-10 \%$ of that at optimal $\mathrm{pH}$ (4.0) and negligible at $\mathrm{pH} 7.0$ [8], but

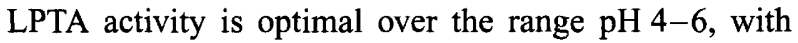
$71 \%$ of optimal activity remaining at $\mathrm{pH} 7.0$ (unpublished data). LPTA may therefore re-acylate lysophospholipids at either acidic or neutral $\mathrm{pH}$, restoring membrane integrity after damage by PLB or heat-stable components of the supernate, or both. Clearly, the role of phospholipases in cryptococcal secretions as virulence factors will depend on the relative activities of the three enzymes in this mixture; predominance of
PLB may exacerbate the toxic effects of other compounds, whereas dominance of LPTA may ameliorate their damage. Membrane lipid degradation sufficient to cause death of the host cells may not be necessary for penetration of tissues by cryptococci, and survival of phagocytes containing live cryptococci could be important for dissemination of the fungus.

In conclusion, cryptococcal phospholipases/transacylases were found to be active in an acidic environment over a relatively wide temperature range and were capable of hydrolysing lung surfactant and membrane lipids at a high rate in vitro. These enzymes, as well as co-secreted heat-stable compounds, may contribute to host membrane lipid degradation and hence virulence in vivo. The identity of the heat-stable components and their mechanisms of action are unknown and are the subject of ongoing investigations.

This work was supported by the National Health and Medical Research Council Grant ID 9937187.

\section{References}

1. Dennis AE. Phospholipases. In: Boyer P (ed) The enzymes, 3rd ed, vol 16, Lipid enzymology. New York, Academic Press. 1983: 307-353.

2. Weinstein J. Synovial fluid leukocytosis associated with intracellular lipid inclusions. Arch Intern Med 1980; 140: $560-561$.

3. Niewoehner DE, Rice $K$, Duane $P$, Sinha AA, Gebhard $R$, Wangensteen $\mathrm{D}$. Induction of alveolar epithelial injury by phospholipase A2. J Appl Physiol 1989; 66: 261-267.

4. Waite M. Phospholipases. In: Vance DE, Vance J (eds) Biochemistry of lipids, lipoproteins and membranes. Elsevier, Amsterdam. 1991: 269-295.

5. Ibrahim AS, Mirbod F, Filler SG et al. Evidence implicating phospholipase as a virulence factor of Candida albicans. Infect Immun 1995; 63: 1993-1998.

6. Birch M, Robson G, Law D, Denning DW. Evidence of multiple extracellular phospholipase activities of Aspergillus fumigatus. Infect Immun 1996; 64: 751-755.

7. Kaneshiro ES. The lipids of Pneumocystis carinii. Clin Microbiol Rev 1998; 11: 27-41.

8. Chen SCA, Wright LC, Santangelo RT et al. Identification of extracellular phospholipase B, lysophospholipase and acyltransferase produced by Cryptococcus neoformans. Infect Immun 1997; 65: 405-411.

9. Chen SCA, Muller M, Zhou JZ, Wright LC, Sorrell TC. Phospholipase activity in Cryptococcus neoformans: a new virulence factor? $J$ Infect Dis 1997; 175: 414-420.

10. Cherniak R, Sundstrom JB. Polysaccharide antigens of the capsule of Crytococcus neoformans. Infect Immun 1994; 62: $1507-1512$.

11. Kwon-Chung KJ, Polacheck I, Popkin TJ. Melanin-lacking mutants of Cryptococcus neoformans and their virulence for mice. J Bacteriol 1982; 150: 1414-1421.

12. Chaturvedi V, Wong B, Newman SL. Oxidative killing of Cryptococcus neoformans by human neutrophils. Evidence that fungal mannitol protects by scavenging reactive oxygen intermediates. J Immunol 1996; 156: 3836-3840.

13. Salyers AA, Whitt DD. Bacterial pathogenesis: a molecular approach. Washington, DC, ASM Press. 1994.

14. Barrett-Bee K, Haynes Y, Wilson RG, Ryley JF. A comparison of phospholipase activity, cellular adherence and pathogenicity of yeasts. J Gen Microbiol 1985; 131: 1217-1221.

15. Bligh EC, Dyer WJ. A rapid method of total lipid extraction and purification. Can J Biochem Physiol 1959; 37: 911-917.

16. Homer J, Roberts JK. The advantages of rapid multipulsing in the routine acquisition of NMR spectra. J Magn Reson 1989; 81: $484-490$. 
17. Shaka AJ, Keeler J, Frenkiel T, Freeman R. An improved sequence for broadband decoupling: WALTZ-16. $J$ Magn Reson 1983; 52: 335-338.

18. May GL, Wright LC, Obbink KG et al. Increased saturated triacylglycerol levels in plasma membranes of human neutrophils stimulated by lipopolysaccharide. J Lipid Res 1997; 38: $1562-1570$.

19. Gross RW, Drisdel RC, Sobel BE. Rabbit myocardial lysophospholipase-transacylase. Purification, characterization, and inhibition by endogenous cardiac amphiphiles. J Biol Chem 1983; 258: $15165-15172$.

20. Duque RE, Fantone JC, Kramer C, Marasco WA, Phan SH. Inhibition of neutrophil activation by $p$-bromophenacyl bromide and its effects on phospholipase $\mathrm{A}_{2} . \mathrm{Br} J$ Pharmacol 1986; 88: 463-472.

21. Martin SJ, Reutelingsperger CPM, McGahon AJ et al. Early redistribution of plasma membrane phosphatidylserine is a general feature of apoptosis regardless of the initiating stimulus; inhibition by overexpression of $\mathrm{Bcl}-2$ and Abl. $J$ Exp Med 1995; 182: 1545-1556.

22. Takahashi M, Banno Y, Nozawa Y. Secreted Candida albicans phospholipase: purification and characterization of two forms of lysophospholipase-transacylase. J Med Vet Mycol 1991; 29: 193-204.

23. Sugatani J, Okumura T, Saito K. Studies of a phospholipase B from Penicillium notatum: substrate specificity and properties of active site. Biochim Biophys Acta 1980; 620: 372-386.

24. Saito K, Sugatani J, Okumura T. Phospholipase B from Penicillium notatum. Methods Enzymol 1991; 197: 446-456.

25. Sugatani J, Kawasaki N, Saito K. Studies on phospholipase B from Pencillium notatum; substrate specificity. Biochim Biophys Acta 1978; 529: 29-37.

26. Rooney SA, Young SL, Mendelson CR. Molecular and cellular processing of lung surfactant. FASEB $J$ 1994; 8: 957-967.

27. Mirbod F, Banno Y, Ghannoum MA et al. Purification and characterization of lysophospholipase-transacylase (h-LPTA) from a highly virulent strain of Candida albicans. Biochim Biophys Acta 1995; 1257: 181-188.

28. Prakobphol A, Leffler H, Hoover CI, Fisher SJ. Palmitoyl carnitine, a lysophospholipase-transacylase inhibitor, prevents Candida adherence in vitro. FEMS Microbiol Lett 1997; 151: 89-94.

29. Witt W, Schweingruber ME, Mertsching A. Phospholipase B from the plasma membrane of Saccharomyces cerevisiae: separation of two forms with different carbohydrate content. Biochim Biophys Acta 1984; 795: 108-116.

30. Dong ZM, Murphy JW. Cryptococcal polysaccharides induce Lselectin shedding and tumor necrosis factor receptor loss from the surface of neutrophils. J Clin Invest 1996; 97: 689-698.

31. Richardson MD, White LJ, McKay IC, Shankland GS. Differential binding of acapsulate and encapsulated strains of Cryptococcus neoformans to human neutrophils. J Med Vet Mycol 1993; 31: 189-199.

32. Kamei K, Brummer E, Clemons KV, Stevens DA. Induction of stress protein synthesis in Histoplasma capsulatum by heat, low $\mathrm{pH}$ and hydrogen peroxide. J Med Vet Mycol 1992; 30: 385-393.

33. Chander A, Johnson RG, Reicherter J, Fisher AB. Lung lamellar bodies maintain an acidic internal $\mathrm{pH}$. $J$ Biol Chem 1986; 261: 6126-6131.

34. Diamond RH, Bennett JE. Growth of Cryptococcus neoformans with human macrophages. Infect Immun 1973; 7: 231-236.

35. Vecchiarelli A, Dottorini M, Pietrella D et al. Role of human alveolar macrophages as antigen-presenting cells in Cryptococcus neoformans infection. Am J Respir Cell Mol Biol 1994; 11: $130-137$. 